\title{
Pulmonary Tuberculosis in Gurkhas in Hong Kong in the period 1984-1987 and the role played by routine radiology in case detection
}

\author{
Major I M Fairley \\ MB, ChB, DMRD, FRCR, RAMC \\ Consultant Radiologist \\ British Military Hospital, Hong Kong \\ Major B J Heap \\ MA, MRCP(UK), DTM+H, RAMC \\ Consultant Physician \\ British Military Hospital Hong Kong
}

\begin{abstract}
SUMMARY: A retrospective study of all cases of pulmonary tuberculosis in Gurkha soldiers and their dependants in Hong Kong in the years 1984-1987 inclusive was performed. In addition all chest X-rays requested for routine purposes and taken at the British Military Hospital, Hong Kong during 1986 were analysed. These studies showed that the current regulations requiring an annual chest $X$-ray for all $G$ urkha soldiers and their dependants were neither cost effective nor productive in screening for active pulmonary tuberculosis.
\end{abstract}

\section{Introduction}

The present regulations ${ }^{1,2,3}$ recognise that Gurkha soldiers and their dependants are a special risk group for pulmonary tuberculosis (PTB) and require that they should have annual chest X-rays (CXRs), performed by mass mini-radiography (MMR) where possible. Pregnant women, however, are not to be X-rayed without clinical indication.

From a number of studies in countries with previously well established screening programmes, it has been demonstrated that the majority of cases of active PTB present with symptoms ${ }^{4}$. In 1983 a World Health Organisation Scientific Group reported that, in the absence of clinical symptoms, repeated chest radiographic examinations have not been shown to be of sufficient clinical value or productivity to justify their continued use ${ }^{5}$.

This study was performed to determine the incidence of PTB in Gurkha Servicemen and their dependants stationed in Hong Kong, to consider the role of routine annual CXRs in the diagnosis of asymptomatic PTB, and to ascertain to what degree the current regulations regarding annual CXRs were being implemented.

\section{Materials and Methods}

A retrospective analysis was made of all cases of PTB occurring in Gurkha Servicemen and their dependants in Hong Kong from 1984 to 1987 inclusive. The records of cases of PTB were sought from two sources notifications to Commander Medical, Headquarters British Forces Hong Kong, and through admission records of British Military Hospital, Hong Kong. The notes and CXRs (including MMR) of all patients recorded as suffering from active PTB were examined.

In addition, a retrospective analysis was made of all CXRs taken in 1986 at British Military Hospital, Hong Kong. The number of CXRs taken for routine screening purposes in Gurkha soldiers and their dependants was determined by identifying CXR requests annotated "routine", "annual", "PULHEEMS", "reengagement", "new arrival from Nepal" and "ex long leave Nepal", as well as those giving no clinicat indication.

\section{Results}

There were forty cases of PTB identified as presentin in the period 1984 to 1987 (Table 1), six of whorf appeared to have been diagnosed from routine radio logical examination. Only four of these cases, howeve 6 two Gurkha soldiers and two Gurkha wives, were truls asymptomatic. The other two, one child and one wif were newly arrived from Nepal and had symptoms of cough, fever and weight loss suggesting the possibility of active PTB. Of the four asymptomatic cases, records of previous CXRs could not be found in three and the $\mathbb{Q}$ fourth had had a normal CXR in the previous year. Three of the four asymptomatic cases had Grade 3 Heaf reactions ${ }^{6}$, and there was no recorded Heaf result in the fourth case.

Table 1

Number of cases of active PTB diagnosed in 1984-1987 inclusive

\begin{tabular}{|c|c|c|c|c|}
\hline \multirow[t]{2}{*}{ Presentation } & \multicolumn{2}{|c|}{ Adults } & \multirow[t]{2}{*}{ Children } & \multirow[t]{2}{*}{ Total } \\
\hline & Male & Female & & \\
\hline Routine CXR & 2 & 3 & 1 & 6 \\
\hline Symptomatic & 21 & 6 & 7 & 34 \\
\hline$\overline{\text { Total }}$ & 23 & 9 & 8 & 40 \\
\hline
\end{tabular}


During the period of this study, twenty-one soldiers presented with symptomatic PTB. All had had previous routine CXRs recorded as normal and six cases had had a normal routine CXR in the year preceding presentation. Of the eight whose tuberculin status was recorded at presentation, all had Heaf reactions of grade three or four. There were six cases of symptomatic PTB recorded in Gurkha wives. Four of these presented with symptoms to their Medical Officer shortly after arrival from Nepal. The two other cases had arrived six and nine months respectively prior to presentation and both had normal CXRs during this period. Heaf status was only recorded in three cases, and was Grade 3 in one case and Grade 4 in two. Of the seven children who had symptoms, four presented immediately on arrival from Nepal. The Heaf reaction was recorded in two, and was Grade 4 in both cases. The other three children were born in Hong Kong and had not travelled outside the Territory; there was no history of contact with PTB. All three had received BCG at birth and were subsequently recorded as having Grade 1 Heaf reactions; their Heaf reactions on presentation were not recorded. None of the children had been previously X-rayed.

In 1986 there were 3,605 routine CXR examinations of Gurkha soldiers and their dependants in the Department of Radiology at BMH Hong Kong. This included 1404 MMR examinations. No cases of active PTB were diagnosed from these CXRs taken for routine screening purposes.

\section{Discussion}

During 1986 the total number of Gurkha soldiers and dependants in Hong Kong was 9,019 ${ }^{7}$. The total number of routine CXR examinations in the same year was 3,605 . It is apparent, therefore, that the current regulations regarding annual CXRs are being far from rigidly implemented.

The number of Gurkha soldiers and dependants in Hong Kong did not change substantially in the period 1984-1987 ${ }^{7}$, so if all Gurkha personnel had been X-rayed annually, a total of some $36,000 \mathrm{CXR}$ examinations would have been performed. This study shows that eleven cases of PTB (four wives and seven children) presented symptomatically before the opportunity for routine chest radiography arose, and nine cases (six soldiers and three wives) presented within a year of having a normal CXR. At best, therefore, twenty cases of PTB might have been detected on routine annual CXR; this is equivalent to one case per $1800 \mathrm{CXRs}$ performed.

The cost of a CXR is conservatively estimated as $£ 9.00^{8}$. This costing takes account of the cost of X-ray staff and materials, but does not include the cost of the maintenance and depreciation of equipment, power, rates and building maintenance, or additional costs such as transportation and loss of working hours. Had these twenty cases been detected on routine radiographic screening the cost per case detected would have been $£ 16,200$. The fact that nine cases in our study presented within a year of having had a normal CXR makes it unlikely that routine screening would in fact have diagnosed all twenty cases prior to the development of symptoms and the cost of detecting an asymptomatic case would, therefore, have been substantially higher.

In conclusion, therefore, it appears that the current regulations requiring annual CXR screening for $\mathrm{PTB}$ in Gurkha soldiers and their dependants are neither cost effective nor efficient. Consideration should be given tos their abandonment.

\section{REFERENCES}

1. AGAI, Issue 63, para 66: 378 .

2. MAI 19/79, Issue 1, DDMS British Forces Hong Kong.

3. MAI 9/80, Issue 27, CRAMC British Forces Hong Kong.

4. POLK L D. No more mass $X$-ray screening for tuberculosis Clin Paediatr. 1976; 15: 983-985.

5. RACOVEANU N T. A rational approach to diagnostic radiology. WHO Chronicle 37; 4: 140-142.

6. Memorandum on Immunological Procedures. Joint Services Publication 311. 1968. Para 105.

7. Gurkha Records Office, Hong Kong, 1987 Personal communication.

8. District Treasurer, S W Surrey Health Authority. 1985. Internal Memorandum.

\section{NOTICE TO ADVERTISERS}

Space orders should be sent to Combined Service Publications Ltd., P.O. Box 4, Farnborough, Hampshire GU14 7LR. Artwork and/or Copy should be forwarded to the same address to arrive by the first day of the month preceding issue, publication dates being February, June and October of each year.

Advertising Rates and Technical Details are as listed in British Rate and Data. 